\title{
Discussion on the Operation and Difficulties of State-owned Media Capital
}

\author{
Li Qingrui ${ }^{1}$, Li Lichao ${ }^{2}$ \\ ${ }^{1,2}$ College of communication art and science, Michigan State University
}

Keywords: State-owned media; Capital operation; Difficult analysis

\begin{abstract}
At present, the capital market is constantly evolving and changing, and the development of state-owned media companies is very difficult. At the same time, the development of various media industries other than state-owned enterprises is also being regulated by the capitalist market. It can be said that the development of media companies under the control of the capital market is changing with each passing day. This paper mainly focuses on the characteristics of the media companies in the development process, and finally divides the operation of contemporary media capital.
\end{abstract}

\section{Capital transformation of traditional media}

Most state-owned media companies are traditional media companies, and their development faces an important turning point. Under the current development situation, more and more industries are facing difficulties in transformation. This kind of corporate choices that emerged in the context of the development of the times will undoubtedly bring great changes to the future development of enterprises. How media companies should cope with the development trend of this era is a more difficult topic. Therefore, media companies need to fully understand their own development and make the right choices.

\section{Case analysis of current the electric and television media Company}

\subsection{The main business structure of Dianguang Media Co. Ltd}

The development path of Radio and television media company has its own characteristics. With the rapid development of network technology, the development scope of Radio and television media company is more and more extensive, and the types of business are also continuously enriched. This development trend is very beneficial to the development of media companies. In the development of media companies, we also need to determine the direction of development to adapt to the increasingly rapid development of media companies. At present, the development of media companies is becoming more and more diversified, with the addition of network information transmission services and concurrently operating various types of services such as hotel tourism and real estate. The following is a table of sub-regional data of the business of Dianguang Media.

Table1. Main business sub-regional situation table in 2005

\begin{tabular}{c|c|c}
\hline Area & Main business income & Proportion \\
\hline Hunan & 148241 & 81.7 \\
\hline Beijing & 19132 & 10.5 \\
\hline Shanghai & 471 & 0.2 \\
\hline Guangdong & 13595 & 7.5 \\
\hline
\end{tabular}

From Table1, we can find that in the electric and television media industry in 2005, the distribution of various businesses is very different. Among them, Hunan's main business income is the highest, accounting for $81.7 \%$ of the total main business income ratio. At the same time, the region with the least income from the main business in the four major regions is Shanghai, accounting for $0.2 \%$ of the total revenue from the main business. Therefore, we have come to the conclusion that different regions have different potentials for developing the TV industry. In the 
future, we need to make a reasonable analysis of different situations and finally determine reasonable regional development requirements.

As mentioned above, the current operation business of Radio and television media company has a lot of room for development. Therefore, in the exploration and development of various businesses, we must pay attention to ensuring the interconnection between various businesses to achieve a win-win situation. First of all, in the advertising business, the branch of Radio and television media company needs to provide the necessary TV channel support to form a nationwide advertising network to better play the role of advertising. In the development of advertising business in multiple regions, the cooperation of advertising companies in various regions is particularly important.

Secondly, in terms of program business, media companies need to pay attention to the production and processing of film and television dramas, and actively produce film and television works with market influence. By publishing the influence of these works companies, we will promote the audience's love for film and television works and promote the company's more stable development in the program business. In addition, in the network business, due to the rapid development of the current network technology, many media companies have followed suit and carried out the necessary business proliferation. Under such circumstances, media companies must prevent the development of other industries from being delayed by the development of network services. Finally, in the development of other businesses. In order to be more responsive to the development of the times, media companies need to accelerate the development of other diverse businesses and ultimately promote the company's better development.

The following is the calculation formula for investment income.

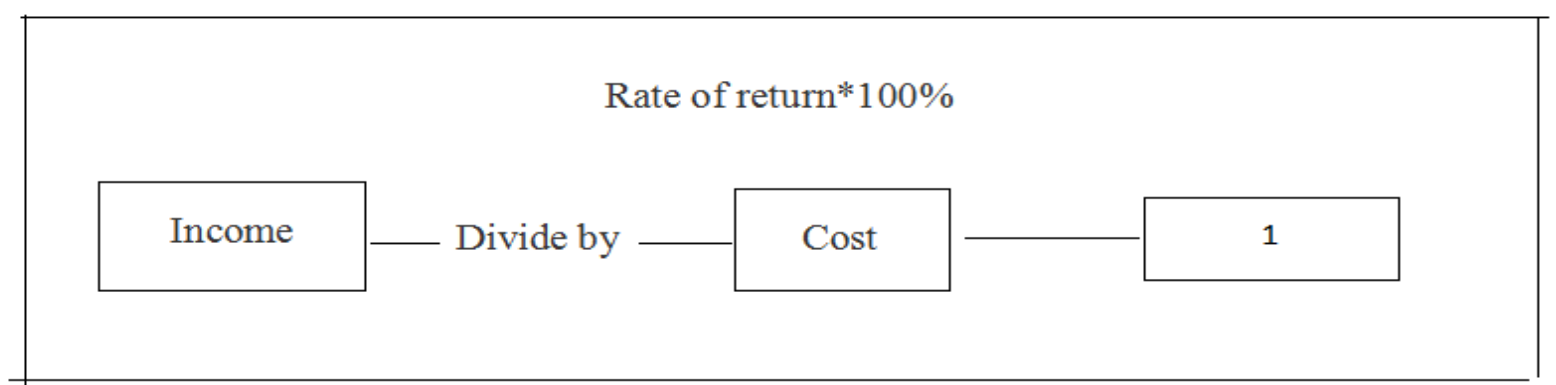

The relationship between income and cost can be seen from the figure. That is, the company's total revenue is equal to the revenue divided by the cost minus 1 and finally multiplied by $100 \%$. We should use this formula reasonably to contribute to our investment company.

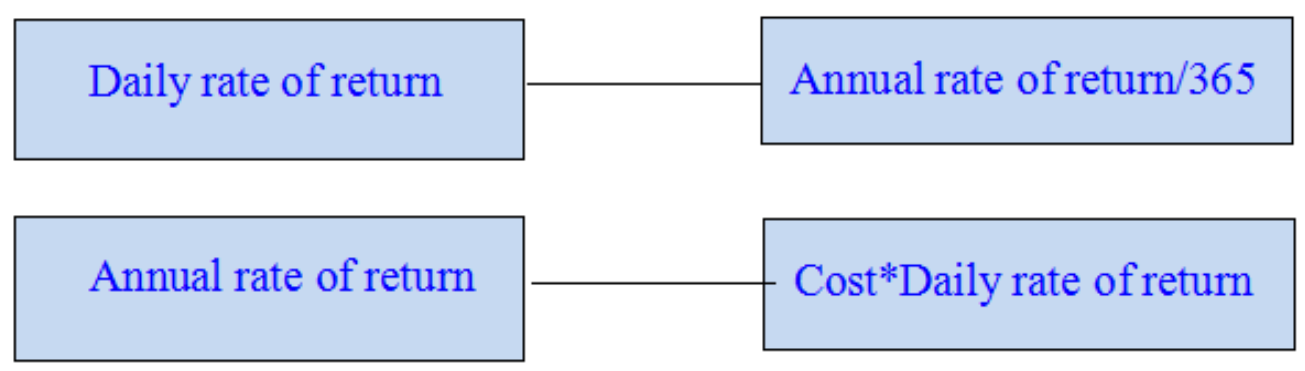

The calculation of annual income can also be performed by such a method. For example, if the cost is 10,000 and the annual rate of return is $8 \%$, the annual rate of return is $10000 * 8 \%=800$, and the daily return is $800 \backslash 365=2.19$.

\subsection{Radio and television media company's advertising operation project}

In the development of Radio and television media company, the development of various businesses has affected the overall development of Radio and television media company. The following is a table for the proportion of advertising revenue of a certain company from 1999 to 2004 in the calendar year. 
Table2. The advertising revenue accounts for the proportion of main income in the past years and the profit of the main business

\begin{tabular}{l|c|c|c|c|c|c}
\hline & $\mathbf{1 9 9 9}$ & $\mathbf{2 0 0 0}$ & $\mathbf{2 0 0 1}$ & $\mathbf{2 0 0 2}$ & $\mathbf{2 0 0 3}$ & $\mathbf{2 0 0 4}$ \\
\hline Advertisement Income & 3.5 & 4.5 & 4.86 & 4.99 & 7.15 & 11.29 \\
\hline Main business income & 4.25 & 5.78 & 6.92 & 6.88 & 9.68 & 15.13 \\
\hline Proportion & 86 & 84 & 71 & 73 & 74 & 75 \\
\hline Gross profit margin & 42 & 80 & 45 & 35.77 & 23.19 & 18.39 \\
\hline
\end{tabular}

The data in the table shows that the proportion of business occupied by advertising business in media listed companies is very large. At the same time, we find that the revenue ratio of advertising business to the main business is declining, which shows that the development of corporate advertising business is subject to the macro control of corporate companies. According to the national advertising business data survey, we find that the current media platform has become more and more dominant in advertising management. Some large advertising companies also value the propaganda power of the media for advertising. Only by strengthening the cooperation between radio and television companies and advertising companies can we promote the better development of media companies and promote the common development and progress of the two industries.

\section{The main problems of the capital market of media listed companies}

\subsection{The degree of marketization is gradually decreasing}

After investigation and analysis, there are five main factors affecting the overall situation of the media capital market.

Table 3. Attitude index map of the overall description of the media capital market

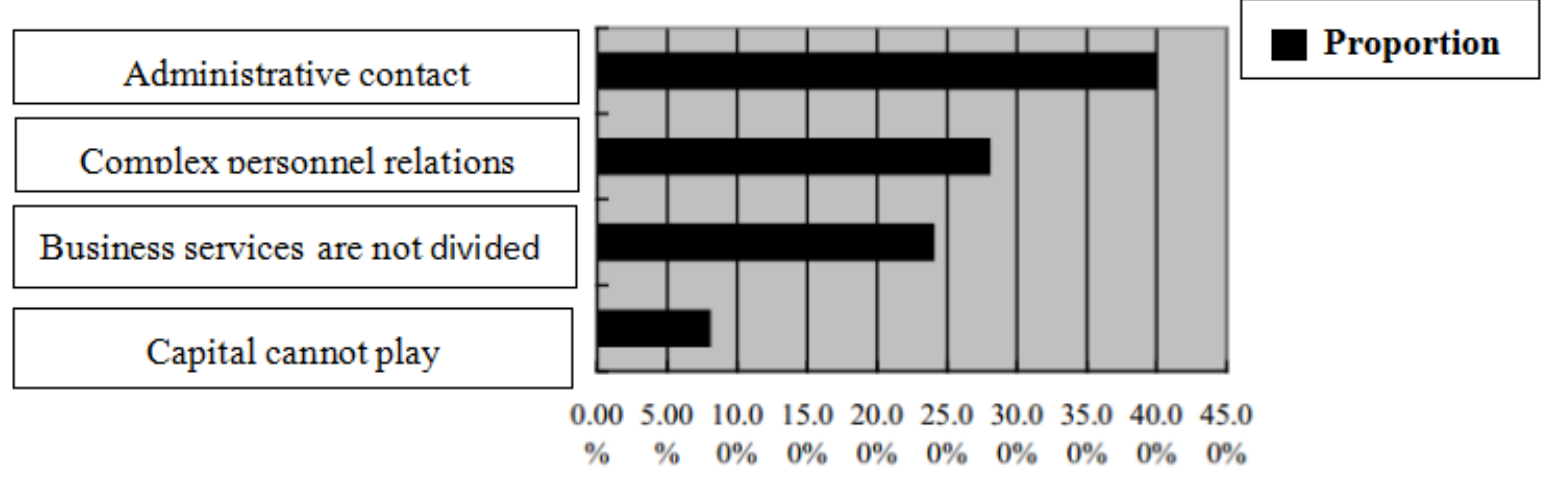

Through the chart, it is found that the proportion of the market with the largest proportion of market distribution is low. In addition, the company's corporate governance structure is not sound. It can be seen that the influence of the company's shareholders on the listed companies in China's media is still very large.

Table 4. More administrative interventions in the media industry

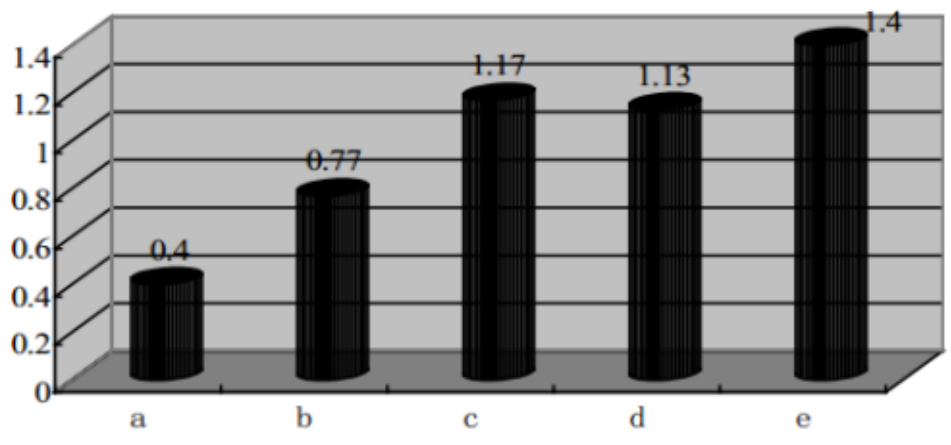

Proportion 


\subsection{Distribution of administrative intervention effects on the media industry}

In the stage of planned economic development, the economic environment has promoted the development of China's media industry and promoted their growth. It is found from the chart that under the influence of the administration, a variety of more prominent research objects have emerged. This paper mainly conducts some research on several objects that are more prominent in the research, and finally draws a clear data analysis table. The business units rely on administrative machinery links, the internal personnel relations in the media enterprises are complex, the propaganda and news services are difficult to separate, and the role of capital cannot fully exert the influence of these four factors. We have proposed some more effective management methods. The first is to reduce administrative interference with the media. The second is to carry out certain reforms with state-owned assets. Once again, it is a channel to broaden financing. Finally, a large-scale national media investment holding company was established.

\section{Conclusion}

In summary, traditional media companies are moving in a gradual transition. For some media companies with better management, it is easier to succeed in capturing opportunities as soon as possible. However, for some media companies that are not in good development, they must combine the development of the company itself to find ways and strategies suitable for their own enterprise development, and ultimately realize the vigorous development of media enterprises.

\section{References}

[1] Cai J. Discussion on the Reform of State-owned Forest Farm in Hubei Province[J]. Hubei Forestry Science \& Technology, 2013.

[2] Cai, J. (2013). Discussion on the reform of state-owned forest farm in hubei province. Hubei Forestry Science \& Technology.

[3] Luo F F, Luo F F. Study on Operation and Management Mode of Public Rental Housing in China, Taking Shanghai City and Chongqing City for Example[J]. American Journal of Sociological Research, 2014, 4(3):102-107.

[4] Luo, Fang Fang, and F. F. Luo. "Study on Operation and Management Mode of Public Rental Housing in China, Taking Shanghai City and Chongqing City for Example." American Journal of Sociological Research4.3(2014):102-107.

[5] Gilligan G, Bowman M. State Capital: Global and Australian Perspectives[J]. Social Science Electronic Publishing, 2014.

[6] Gilligan, G., \& Bowman, M. (2014). State capital: global and australian perspectives. Social Science Electronic Publishing. 